University of Wollongong

Research Online

Faculty of Health and Behavioural Sciences -

Papers (Archive)

Faculty of Science, Medicine and Health

$1-1-2012$

\title{
Using the theory of planned behaviour and implementation intentions to predict and facilitate upward family communication about mammography
}

J L. Browne

University of Wollongong, jlb96@uow.edu.au

A Y. C Chan

University of Wollongong, amychan@uow.edu.au

Follow this and additional works at: https://ro.uow.edu.au/hbspapers

Part of the Arts and Humanities Commons, Life Sciences Commons, Medicine and Health Sciences Commons, and the Social and Behavioral Sciences Commons

\section{Recommended Citation}

Browne, J L. and Chan, A Y. C: Using the theory of planned behaviour and implementation intentions to predict and facilitate upward family communication about mammography 2012, 655-673.

https://ro.uow.edu.au/hbspapers/2721

Research Online is the open access institutional repository for the University of Wollongong. For further information contact the UOW Library: research-pubs@uow.edu.au 


\title{
Using the theory of planned behaviour and implementation intentions to predict and facilitate upward family communication about mammography
}

\begin{abstract}
Regular mammography facilitates early detection of breast cancer, and thus increases the chances of survival from this disease. Daughter-initiated (i.e. upward) communication about mammography within mother- daughter dyads may promote mammography to women of screening age. The current study examined this communication behaviour within the context of the Theory of Planned Behaviour (TPB), and aimed to bridge the intention-behaviour gap by trialling an implementation intention (II) intervention that aimed to facilitate upward family communication about mammography. Young women aged 18-39 $(\mathrm{N} 1 / 4116)$ were assigned to either a control or experimental condition, and the latter group formed Ils about initiating a conversation with an older female family member about mammography. Overall, those who formed Ils were more likely to engage in the target communication behaviour, however the intervention was most effective for those who reported low levels of intention at baseline. Perceived behavioural control emerged as the most important variable in predicting the target behaviour. The altruistic nature of this behaviour, and the fact that it is not wholly under volitional control, may have contributed to this finding. Future studies that systematically explore the relative roles of intention and perceived behavioural control in behaviours of this nature are warranted.
\end{abstract}

\section{Keywords}

intentions, mammography, about, communication, family, implementation, behaviour, upward, facilitate, theory, predict, planned

\section{Disciplines}

Arts and Humanities | Life Sciences | Medicine and Health Sciences | Social and Behavioral Sciences

\section{Publication Details}

Browne, J. L. \& Chan, A. Y. C. (2012). Using the theory of planned behaviour and implementation intentions to predict and facilitate upward family communication about mammography. Psychology and Health: an international journal, 27 (6), 655-673. 
This article was downloaded by: [University of Wollongong]

On: 08 J une 2012, At: 00:00

Publisher: Routledge

Informa Ltd Registered in England and Wales Registered Number: 1072954 Registered

office: Mortimer House, 37-41 Mortimer Street, London W1T 3J H, UK

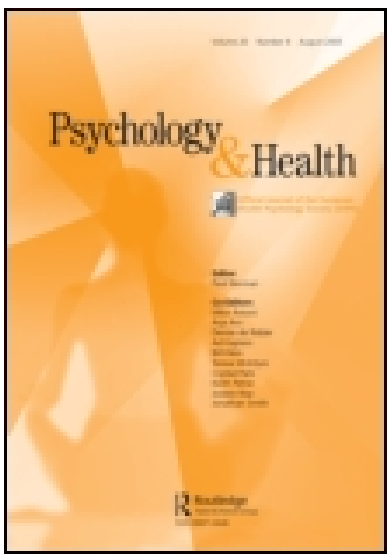

\section{Psychology \& Health}

Publication details, including instructions for authors and subscription information:

http:// www.tandfonline.com/loi/gpsh20

\section{Using the Theory of Planned Behaviour and implementation intentions to predict and facilitate upward family communication about mammography}

J.L. Browne ${ }^{a} \&$ A.Y.C. Chan ${ }^{\text {a }}$

a School of Psychology, University of Wollongong, Wollongong, NSW 2522, Australia

Available online: 07 Oct 2011

To cite this article: J.L. Browne \& A.Y.C. Chan (2012): Using the Theory of Planned Behaviour and implementation intentions to predict and facilitate upward family communication about mammography, Psychology \& Health, 27:6, 655-673

To link to this article: http:// dx.doi.org/ 10.1080/ 08870446.2011.615396

\section{PLEASE SCROLL DOWN FOR ARTICLE}

Full terms and conditions of use: http://www.tandfonline.com/page/terms-andconditions

This article may be used for research, teaching, and private study purposes. Any substantial or systematic reproduction, redistribution, reselling, loan, sub-licensing, systematic supply, or distribution in any form to anyone is expressly forbidden.

The publisher does not give any warranty express or implied or make any representation that the contents will be complete or accurate or up to date. The accuracy of any instructions, formulae, and drug doses should be independently verified with primary sources. The publisher shall not be liable for any loss, actions, claims, proceedings, demand, or costs or damages whatsoever or howsoever caused arising directly or indirectly in connection with or arising out of the use of this material. 


\title{
Using the Theory of Planned Behaviour and implementation intentions to predict and facilitate upward family communication about mammography
}

\author{
J.L. Browne* ${ }^{\dagger}$ and A.Y.C. Chan \\ School of Psychology, University of Wollongong, Wollongong, NSW 2522, \\ Australia \\ (Received 17 November 2010; final version received 14 August 2011)
}

\begin{abstract}
Regular mammography facilitates early detection of breast cancer, and thus increases the chances of survival from this disease. Daughter-initiated (i.e. upward) communication about mammography within motherdaughter dyads may promote mammography to women of screening age. The current study examined this communication behaviour within the context of the Theory of Planned Behaviour (TPB), and aimed to bridge the intention-behaviour gap by trialling an implementation intention (II) intervention that aimed to facilitate upward family communication about mammography. Young women aged 18-39 $(N=116)$ were assigned to either a control or experimental condition, and the latter group formed IIs about initiating a conversation with an older female family member about mammography. Overall, those who formed IIs were more likely to engage in the target communication behaviour, however the intervention was most effective for those who reported low levels of intention at baseline. Perceived behavioural control emerged as the most important variable in predicting the target behaviour. The altruistic nature of this behaviour, and the fact that it is not wholly under volitional control, may have contributed to this finding. Future studies that systematically explore the relative roles of intention and perceived behavioural control in behaviours of this nature are warranted.
\end{abstract}

Keywords: Theory of Planned Behaviour; implementation intentions; mammography; family communication

\section{Introduction}

\section{Breast cancer and mammography}

Breast cancer is a significant international health problem. One in eight women will be diagnosed with breast cancer in her lifetime, and it is the second most common cause of cancer-related deaths in women (second only to lung cancer) in developed countries such as the United States (National Cancer Institute, 2004), England (Cancer Research UK, 2007) and Australia (Australian Institute of Health and

\footnotetext{
*Corresponding author. Email: jessica.browne@deakin.edu.au

$\uparrow$ Author Jessica Browne is now at The Australian Centre for Behavioural Research in Diabetes, Deakin University.
} 
Welfare \& National Breast and Ovarian Cancer Centre, 2009). An important risk factor for the development of breast cancer in women is age, with the majority of breast cancer cases diagnosed in women over the age of 50 (Australian Institute of Health and Welfare \& National Breast and Ovarian Cancer Centre, 2009; Horner et al., 2009; McPherson, Steel, \& Dixon, 2000). Screening mammography is currently the best option for reducing the impact and the mortality rate of breast cancer, with evidence from meta-analyses of randomised controlled trials suggesting that the preventive health benefits of mammography are most apparent for women over the age of 50 (Humphrey, Helfand, Chan, \& Woolf, 2002; Kerlikowske, Grady, Rubin, Sandrock, \& Ernster, 1995).

Most developed countries provide free population-based screening programs, with relatively high participation rates amongst eligible women. For example, the program in the United Kingdom has a $74 \%$ participation rate (National Health Service (NHS), 2009), while New Zealand has a 64\% participation rate (Simmons \& Robson, 2008). As in the United Kingdom and New Zealand, Australia's screening program (BreastScreen Australia) actively recruits target women (defined in Australia as those aged 50-69) with a goal of $70 \%$ in participation rate. Despite active recruitment and reminders via mail-outs, as well as constant media campaigns, BreastScreen Australia reports a participation rate of only $57.1 \%$. Hence, innovative interventions that aim to promote mammography to target women and increase the uptake rate of mammographic screening are warranted.

\section{Upward family communication about mammography}

Interpersonal communication is a viable means of health promotion (Rimer, 1998), and the mother-daughter dyad may be a particularly promising context within which to explore this notion. Previous research that has examined interpersonal communication about health within the mother-daughter dyad has largely focussed on downward family communication, that is, a mother's influence on her daughter(s). Upward family communication - the role a daughter could play in her mother's health decision-making and behaviour - has received less attention in the research, but there is existing evidence to suggest that this is a viable avenue of exploration. For example, on the basis of a large qualitative study with mothers and their daughters, Fingerman $(1997,2001)$ reported that the mother-daughter relationship is one of the most stable throughout the lifespan. Further, daughters are likely to be a source of support and assistance for their mothers as they age, increasing their position of influence, and this is perhaps especially true when it comes to matters of health (McGraw \& Walker, 2004). Finally and importantly, targeting younger women and prompting them to communicate with their mothers about preventive health behaviours enables the provision of information to two generations simultaneously (Mosavel, Simon, \& Van Stade, 2006).

Some recent work has also begun to systematically explore upward communication about health between mothers and their daughters. Mosavel et al. (2006) found that $70 \%$ of mothers in a South African sample reported asking their adolescent daughters for advice and, of these, $14 \%$ reported specifically asking their daughters for advice about health issues. Focus groups with African-American and Latina adolescent daughters found that participants would often pass on information about things they learned at school to their mothers, such as information on 
smoking, weight loss, contraception, and cancer screening. Participants also reported that their mothers often heeded their advice (Mosavel \& Thomas, 2009). Convergent evidence for the daughters' self-reports was provided in a related focus group study with mothers of the same demographic (Mosavel, 2009). Through observations and interviews with Filipino and Mexican mothers and their adult daughters, Washington, Burke, Joseph, Guerra, and Pasick (2009) found evidence of mothers consulting their adult daughters for health advice, as well as evidence of daughters facilitating the health care of their mothers. A recent interview study with Australian mothers and their adult daughters provided similar evidence. Results of this study suggested that the daughters spontaneously initiated conversations with their mothers about a range of health topics, and that often the purpose of these conversations was to encourage their mother's health behaviour change. Nonetheless, crucial to the current paper, it was also found that upward communication about mammography did not occur unprompted (Browne \& Chan, 2011). The study reported in the current paper aimed to further explore the potential for young women to influence their mother's health behaviour by trialling an intervention that aimed to prompt upward family communication about mammography, in order to promote mammography to mothers of screening age.

\section{Theory of planned behaviour as applied to upward family communication}

The current study utilised the Theory of Planned Behaviour (TPB) model as a framework for predicting and facilitating upward family communication about mammography. The TPB posits that there are two proximal motivational predictors of behaviour: intention and perceived behavioural control. The stronger a person's intentions to perform a particular behaviour, the more likely the behaviour is to be performed (Ajzen \& Madden, 1986). Intention is determined by one's attitude toward performing the behaviour (overall evaluation of the behaviour), subjective norms (perception of the approval/disapproval of significant others), and perceived behavioural control (perception of how easy or difficult it is to engage in a behaviour), and thus mediates the effect of these other variables on actual behaviour. Perceived behavioural control may also directly influence behaviour, particularly in circumstances where actual volitional control is reduced (Ajzen, 1991; Armitage \& Conner, 2001). A number of meta-analytic reviews have been conducted to assess the predictive power of the TPB as applied to health behaviour (e.g. Ajzen, 1991; Armitage \& Conner, 2001; Cooke \& French, 2008; Godin \& Kok, 1996; Hardeman et al., 2002), with results demonstrating that the TPB model effectively predicts intention, and that the model can account for considerable variance in actual behaviour. Further, a systematic review by Hardeman et al. (2002) of 24 TPB-based interventions reported that two thirds of studies indicated that such interventions appeared to be effective in facilitating the desired behaviour change.

There is also some evidence that the TPB has utility in predicting health communication behaviour. Hyde and White (2009) demonstrated that a combined model of attitude, subjective norm and perceived behavioural control successfully predicted intention to engage in family communication about organ donation. Similarly, Barsevick et al. (2008) found that global attitudes, specific social norms and perceived behavioural control were all significant predictors of women's intentions to communicate the results of a BRCA1/BRCA2 genetic test to family 
members. One limitation of these studies is that they did not measure actual performance of the target behaviour. The current research extends the findings of this previous work by applying the TPB to a novel health communication behaviour (upward family communication about mammography), and also by evaluating the behavioural outcomes of an intervention informed by the TPB.

\section{The intention-behaviour gap}

While the TPB is an effective and frequently used model for predicting and explaining health-related behaviour (Armitage \& Conner, 2001; Cooke \& French, 2008; Godin \& Kok, 1996), there is a well-documented intention-behaviour gap, meaning that the correlation between intention and behaviour is unsatisfactory (Conner \& Armitage, 1998; Conner \& Norman, 2005; Hardeman et al., 2002; Renner \& Schwarzer, 2003; Sheeran \& Orbell, 1998). TPB-based motivational interventions that aim to simply increase intention have generally failed to facilitate behaviour change (e.g. Parker, Stradling, \& Manstead, 1996; Sheeran \& Silverman, 2003; Webb \& Sheeran, 2006). This suggests that the TPB model alone is insufficient. A criticism of the TPB model is that it focuses exclusively on the motivational phase of action, and neglects the volitional phase of behavioural performance where the intention is translated into behaviour (e.g. Conner \& Norman, 2005; Renner \& Schwarzer, 2003). Hence, many researchers have begun to consider supplemental strategies that operate volitionally (as opposed to motivationally), assisting the conversion of intention into behaviour (e.g. Brandstatter, Lengfelder, \& Gollwitzer, 2001; Epstude \& Roese, 2008; Gollwitzer, 1993; Orbell, Hodgkins, \& Sheeran, 1997; Page \& Colby, 2003; Sheeran \& Orbell, 2000; Sheeran \& Silverman, 2003; Steadman \& Quine, 2004).

This shift in research attention has been largely facilitated by Gollwitzer's (1993) work with implementation intentions, which are plans that specify how, where and when a goal-directed behaviour will be implemented. Consider a young woman who decides, "I want to check to see if my mum has regular mammograms". This is a statement of a goal-directed behaviour, or behavioural intention. However, the young woman will be more likely to achieve this goal if she forms a plan for how the goal-directed behaviour will be implemented, that is, if she forms an implementation intention (II), for example, 'Next time I am watching television with my mum and a mammography advertisement comes on, I will ask her if she has regular mammograms.' In doing this, the woman specifies cues such as 'when' and 'where' that then become increasingly cognitively accessible (Gollwitzer, 1999). Consequently, these environmental or situational cues are more likely to be attended to when they appear, and should trigger the stated behaviour in a manner much like habit, without conscious thought (Brandstatter, Lengfelder, \& Gollwitzer, 2001). Thus, forming IIs should increase the rate of conversion of behavioural intentions into actual behaviour.

Gollwitzer and his colleagues have provided extensive support for this general proposition (e.g. Brandstatter et al., 2001; Gollwitzer, 1993, 1999). Of particular relevance to the current study, IIs have been successfully used to increase behavioural performance of a range of health-promoting behaviours, including choosing healthy foods (Adriaanse, de Ridder, \& de Wit, 2009; Armitage, 2007; de Nooijer, de Vet, Brug, \& de Vries, 2006), engaging in physical activity (Arbour \& Ginis, 2009; Milne, Orbell, \& Sheeran, 2002), and screening for cancer (Prestwich 
et al., 2005; Rutter, Steadman, \& Quine, 2006; Sheeran \& Orbell, 2000; Steadman \& Quine, 2004). In particular, IIs have been employed as a supplement to the TPB model in an attempt to increase translation of intention to behaviour. IIs have been demonstrated to facilitate the conversion of intention into behaviour, and thus increase the rate of performance of a range of health behaviours, including exercise behaviour (Brickell, Chatzisarantis, \& Pretty, 2006; Rise, Thompson, \& Verplanken, 2003), cervical cancer screening (Sheeran \& Orbell, 2000), and breast selfexamination (Orbell, Hodgkins, \& Sheeran, 1997). Furthermore, there is recent evidence to suggest that IIs mediate the relationship between intention and behaviour with regard to physical activity and dental hygiene behaviours (Wiedemann, Schuz, Sniehotta, Scholz, \& Schwarzer, 2009), and that IIs moderate and mediate the intention-behaviour relationship with regard to use of sunscreen (Van Osch et al., 2008).

\section{The current study}

We report a study that piloted an II intervention that operated within a TPB framework to target upward family communication about mammography. This study represents a novel application of IIs to everyday health communication behaviour. Upward communication about mammography, unlike many of the other health-related behaviours to which the TPB and IIs have been applied, is somewhat altruistic. Unlike increasing physical activity, developing a healthier diet, and performing self-examinations for cancer (e.g. breast, testicular), upward family communication about mammography does not bring about any immediate benefits to the conversation initiator (the daughter). Thus, this study may represent a more stringent test of IIs as compared to previous studies. The present pilot intervention required young women to form IIs by specifying when, where and how they would initiate upward family communication about mammography, and it was expected that this may be a way of prompting them to enact this novel behaviour. We predicted that: (1) The TPB variables of attitude, subjective norm, and perceived behavioural control would predict intention, and the TPB model as a whole would predict upward family communication behaviour, with only intention and perceived behavioural control independently predicting behaviour; (2) participants who formed IIs would be more likely to perform the desired behaviour than control participants; and (3) participants with a high level of intention would be more susceptible to the effects of IIs, as we expected that IIs would increase the performance of the target behaviour by facilitating the conversion of a pre-existing intention into behaviour.

\section{Method \\ Participants}

Female undergraduates at a medium-sized Australian university who were aged 18-39 years $(M=20 ; 09)$ participated voluntarily in this two-stage pilot intervention, in exchange for partial course credit or a coffee voucher. This particular age range was selected because the participants were not of screening age themselves, but they were likely to have an older female family member in the age range for which regular screening is recommended (50-69 years). 
A $14 \%$ attrition rate was observed between the intervention phase, referred to as Stage One $(N=135)$, and the follow-up phase, referred to as Stage Two $(N=116)$. No significant differences on demographic or TPB variables were observable between those participants who returned for Stage Two and those who did not $[F(1,133)$ values from $0.06-3.35$, all $p>0.05]$, nor did the attrition affect one condition disproportionately to the other. Thus, participants without a full data set were excluded from the analyses, leaving a final sample of $N=116$ (60 control participants, and 56 participants in the experimental condition).

\section{Materials}

\section{Stage One questionnaire}

This questionnaire began with a brief information paragraph, highlighting age as the greatest risk factor for developing breast cancer, and outlining the benefits of regular screening mammography. Participants were then asked if they had ever discussed mammography with an older female family member in the past. The term 'older female family member' was used throughout the questionnaire to allow for the possibility that young women have discussed, or would consider discussing, mammography with a relative other than their mother (e.g. grandmother).

The same questionnaire booklet also included 15 items to assess TPB variables in relation to initiating a conversation about mammography with an older female family member in the near future. Attitude, perceived behavioural control, subjective norm and intention were measured using items with a seven-point Likert scale (anchors varied between items, and were counterbalanced).

Attitude was assessed with five items that used the stem 'For me to initiate a conversation about mammography with an older female family member in the next two months is/would be...', and responses were required on a different scale for each item (extremely harmful-extremely beneficial, very unimportant-very important, very desirable-very undesirable, extremely worthwhile-extremely worthless, very foolishvery wise). Items were reverse-scored where necessary, so that higher scores indicated a more positive attitude towards the behaviour. Reliability was satisfactory $(\alpha=0.75)$, and item scores were summed to produce an overall attitude score (possible range: 5-35). Similarly, perceived behavioural control was measured by six items which were summed to produce an overall score, reverse-scoring where necessary so that higher scores reflected higher perceived behavioural control ( $\alpha=0.84$, possible range: $6-42$ ). The items asked participants to rate their confidence (very confident-very unconfident), perceived ease of initiating the conversation (very easy-very difficult) and control (outside my control-within my control). Three additional behavioural control items, 'I feel capable of initiating a conversation about mammography in the next two months with an older female family member', 'If I wanted to, I could easily initiate a conversation with an older female family member about mammography within the next two months' and 'I am discouraged from initiating a conversation about mammography with an older female family member in the next two months because I'm unsure how to raise the topic' required a response on a strongly disagree-strongly agree scale.

Three items were used to assess intention, which were reverse-scored as appropriate and summed as was done with the other scales $(\alpha=0.88$, possible range: 3-21). Participants responded to the statements, 'I will try to have a 
conversation about mammography with an older female family member in the next two months' (definitely true-definitely false), 'I plan to have a conversation about mammography with an older female family member in the next two months' (very unlikely-very likely) and 'I intend to initiate a conversation with an older female family member about mammography within the next two months' (very unlikely-very likely).

A single item was used to measure subjective norm, as recommended by Ajzen and Fishbein (1980); 'Most people whose opinions I value would approve of me talking to an older female family member about mammography within the next two months' (definitely true-definitely false).

The following paragraph appeared at the end of the questions:

It is important for young women to discuss mammography with female family members who are in the 'at risk' age group (over 50 years old). It is important because it helps raise awareness about breast cancer screening: both its availability and its benefits. Over the next 2 months or so, you may consider discussing mammography with an older female family member.

Both the experimental and control groups received this instruction so as not to create differential experimenter demand effects between groups. Participants allocated to the experimental group were exposed to an additional paragraph and task, which was the II intervention:

You are more likely to initiate a conversation about mammography with an older female family member if you decide when, where, and how this might take place, and with whom. Write these decisions down in the space provided below.

Participants in the experimental group were then guided to form an II by asking them to specify (by writing in a space provided) with whom they would initiate the conversation, when and where the conversation would take place and how they would begin the conversation.

The questionnaire also included a short form that asked all participants to record demographic details of interest such as their age, student status, marital status, income and family history of breast cancer.

\section{Stage Two questionnaire}

This questionnaire was designed to determine whether or not participants engaged in the desired behaviour after participating in Stage One. The questionnaire asked participants to report whether or not they initiated a conversation about mammography with an older female family member and, if so, who the family member was (e.g. mother, grandmother). Intention was re-assessed with the same three items used in the Stage One questionnaire, to ensure that the II intervention acted upon volition, rather than simply increasing motivation (Milne et al., 2002).

\section{Procedure}

For Stage One, participants were tested in a classroom setting with groups of up to 10. Informed consent was obtained prior to the commencement of the study tasks. Random allocation of each testing session to either the experimental condition (exposed to the II intervention) or control condition (information only) served to ensure that all participants in the classroom were engaged in identical tasks. 
Randomisation to each group was achieved by flipping a coin prior to the commencement of the session, and thus the experimenter was not blind to the randomisation.

Participants were instructed to generate a unique participant code that maintained their anonymity, and to use this as a marker on the questionnaires and to allow their data to be matched across stages. Participants were advised that Stage Two would consist of another questionnaire on a related topic, thus reducing the likelihood of experimenter demand effects. Stage One took 40-50 minutes to complete, depending on the assigned condition.

Data collection for Stage Two occurred approximately eight weeks after Stage One in a small group setting, with a maximum of four participants at a time. Upon completion of the questionnaire, participants were debriefed and were provided with two copies of a mammography information brochure issued by BreastScreen NSW (a subsidiary of BreastScreen Australia). Participants were encouraged to keep one copy for themselves, and pass on the second copy to their conversation partner, or if they did not initiate a conversation about mammography, to pass the brochure onto a female family member in the target age range for regular screening. Stage Two took approximately 10 minutes to complete. The study was approved by the University's Human Research Ethics Committee.

\section{Results}

Most participants were single (87\%), full time university students $(95 \%)$ with no family history of breast cancer $(58 \%$, with an additional $14 \%$ indicating they were unsure about their family history). The experimental and control groups were equivalent at Stage One with regard to all TPB variables ( $F$ range $0.40-1.21$, all $p>0.05)$, and most demographic variables $\left(\chi^{2}\right.$ range $0.16-6.72$, all $\left.p>0.05\right)$, with the exception of age $[F(1,114)=4.21, p<0.05]$. Participants in the control group $(M=21 ; 7)$ were significantly older than those in the experimental group $(M=19 ; 11)$, however the difference in mean age between groups was just 20 months, with both the control and experimental groups having mean ages typical of undergraduate students. Thus this cohort difference, while statistically significant, is unlikely to have influenced the experimental manipulation.

Attitude, subjective norm and perceived behavioural control were regressed on intention. Consistent with the TPB model and our study hypothesis, these variables significantly predicted levels of intention, $F(3,112)=17.71, p<0.001, r^{2}=0.30$. Both attitude and perceived behavioural control were significant independent predictors of intention (Table 1). Subjective norm did not independently predict intention, contrary to our study hypothesis.

The desired behavioural outcome for this intervention was the successful initiation of a conversation about mammography with an older female

Table 1. Attitude, subjective norm and perceived behavioural control regressed on intention.

\begin{tabular}{lcrc}
\hline TPB variable & Standardised $\beta$ & $t$ & $p$ \\
\hline Attitude & 0.46 & 5.60 & 0.00 \\
Subjective norm & -0.14 & -1.75 & 0.08 \\
Perceived behavioural control & 0.20 & 2.39 & 0.02 \\
\hline
\end{tabular}


family member. Fifty participants $(43 \%, 30$ of whom were from the experimental group) reported having initiated the desired behaviour, and almost all of these participants $(94 \%)$ reported having had the conversation with their mothers. To examine what variables predicted performance of this behaviour, a backward logistic regression was performed, with the binary dependent variable being whether or not the young women initiated a conversation about mammography with an older female family member. Independent variables were selected for inclusion in the logistic regression if a univariate analysis returned a result of $p<0.25$ (Hosmer \& Lemeshow, 1989). The results of the univariate analyses demonstrated that the demographic variables of household income $\left[\chi^{2}(4)=3.00\right]$, student status $\left[\chi^{2}(1)=0.25\right]$ and family history of breast cancer $\left[\chi^{2}(2)=1.37\right]$ were not likely to predict the target behaviour (all $p>0.25$ ), and thus were not included in the multivariate analysis. Similarly, subjective norm was excluded from the logistic regression analysis on the basis of the univariate results $(F(1,114)=0.69$, $p>0.25)$.

The backward regression procedure excluded variables from the logistic model based on the likelihood ratio, with past behaviour, attitude and marital status all being removed at subsequent steps of the analyses. The resulting model from each step was not a significantly better fit than the preceding model (all $p>0.05$ ), though the final logistic model was significantly better at predicting the dependent variable $\left(67 \%\right.$ of cases correctly classified, $\left.r^{2}=0.18\right)$ than a constant-only model, $[59 \%$ of cases correctly classified, $\chi^{2}(5)=26.27, p<0.001$ ] and thus there is no disadvantage in retaining the more parsimonious, final model. Beta scores, odds ratios and $p$ values for the predictor variables included in the final logistic model are displayed in Table 2 .

Consistent with our predictions, perceived behavioural control was a strong independent predictor of whether the participant initiated upward family communication about mammography; however, Stage One intentions only approached significance as an independent predictor. Condition also emerged as a marginally significant independent predictor, meaning that those who formed IIs were more likely to have initiated upward family communication about mammography. This gives some indication that the intervention was successful overall. Age of the participant made no independent contribution to the prediction of the desired behaviour.

However, this analysis does not evaluate the mechanism by which IIs are proposed to operate: that is, increasing the conversion of intention into behaviour. For the II to operate volitionally, an intention has to be present in the first place. Therefore, to test whether the IIs formed in this study increased the conversion of intention to behaviour, a separate analysis was run for those who reported a higher

Table 2. Predictor variables in the final logistic model.

\begin{tabular}{lccc}
\hline Predictor variable & $\beta$ & $\operatorname{Exp}(\beta)$ & $p$ \\
\hline Age & 0.01 & 1.00 & 0.12 \\
Condition & -0.81 & 0.44 & 0.05 \\
Perceived behavioural control & -0.11 & 0.89 & 0.00 \\
Intention & -0.09 & 0.91 & 0.06 \\
\hline
\end{tabular}


level of intention at baseline. To identify participants who had higher intentions at Stage One, a tertile split was performed on the data by Stage One intention score, with those scoring in the highest tertile being classified as high intenders (range $=15$ 21), and those scoring on the lowest tertile being classified as low intenders (range $=3-10$ ). Participants who scored in the second tertile (scores of 11-14) were excluded from this analysis. Table 3 displays descriptive statistics for the high intender and low intender groups, as well as the frequency data, which outlines the proportion of participants from each intender group and from each condition that engaged in the desired behaviour.

As expected based on the way the groups were created, mean intention scores were significantly different between the high intender and low intender groups $[F(1$, $70)=410.45, p<0.001]$, and there were no differences in intention scores between conditions within either the high intender $[F(1,33)=1.03, p>0.05)$ or low intender $[F(1,35)=1.14, p>0.05]$ groups.

Two separate Chi Squared tests were performed, one on each intender group, with condition and behavioural performance (yes/no) being the categorical variables. The results of these analyses indicated that although there was a trend for high intenders who formed IIs to be more likely than control group high intenders to initiate the desired behaviour $(56 \%$ versus $41 \%)$, this relationship was not significant, $\chi^{2}(1)=0.72, p>0.05$. However, in contrast to expectations, significantly more low intenders who formed IIs had a conversation, as compared to low intender controls $(44 \%$ versus $10 \%), \chi^{2}(1)=5.78, p<0.05$, suggesting that the intervention did not operate by converting existing intentions into behaviour.

One possible explanation for this could be that participating in the II intervention simply increased the level of intention from baseline, and therefore those classed as low intenders at baseline actually became high intenders after forming IIs. If this were the case, it would indicate that the II intervention did not operate volitionally as expected, but motivationally, simply increasing the level of intention for those with a low baseline score, and the elevated level of intention then facilitated behavioural performance. If this process occurred, we would expect participants who formed IIs to experience a greater increase in intention scores between Stages One and Two as compared to controls. A 2 (condition) x 2 (intention scores at Stages One and Two) x

Table 3. Descriptive statistics of intention scores at baseline and outcomes by condition and intention group.

\begin{tabular}{lcc}
\hline & \multicolumn{2}{c}{ Condition } \\
\cline { 2 - 3 } Intention group & Experimental & Control \\
\hline High intenders & 18 & \\
$N$ & 17.44 & 17 \\
$M$ & 1.92 & 2.05 \\
SD & $56 \%$ & $41 \%$ \\
Proportion of participants who initiated conversation & & \\
Low intenders & 16 & 21 \\
$N$ & 7.13 & 6.35 \\
$M$ & 2.45 & 2.35 \\
SD & $44 \%$ & $10 \%$ \\
Proportion of participants who initiated conversation & & \\
\hline
\end{tabular}


2 (high intender or low intender at Stage 1) mixed-design ANOVA demonstrated that overall intention scores rose significantly between Stages One $(M=11.83)$ and Two $(M=13.85), F(1,67)=19.19, p<0.01$, and that the intention $\mathrm{x}$ intender group effect was significant, $F(1,67)=86.08, p<0.01$. Follow-up pairwise comparisons indicated that while those classified as low intenders at Stage 1 (intention score $M=6.69)$ reported higher intention levels at Stage $2(M=12.83)$, high intenders experienced a slight drop in intention scores between Stages One $(M=17.11)$ and Two $(M=14.89)$, however even at Stage Two their mean intention scores were significantly higher than those of the low intender group $(F(1,69)=4.85, p<0.05)$. This suggests that participation in the study alone increased levels of intention to initiate upward family communication about mammography for those who originally reported low levels of intention, and this occurred regardless of condition, with the intention $\mathrm{x}$ intender group $\mathrm{x}$ condition $[F(1,67)=0.73]$ and the intention $\mathrm{x}$ condition $[F(1,67)=0.01]$ interactions being non-significant (all $p>0.05)$. The main effect of condition was also non-significant, $F(1,67)=1.63, p>0.05$.

A final analysis of the effects of the II intervention was conducted by examining subgroups of women based on their behavioural control beliefs (i.e. their perceived behavioural control scores). There were two reasons for conducting this analysis. Firstly, perceived behavioural control emerged as the strongest predictor of behaviour in the current study, and this result suggests that further analysis of this variable is warranted. Secondly, Rutter, Quine, Steadman, and Thompson (2007) set a precedent for such an analysis, with their results suggesting that an II intervention worked best for women who initially had low perceived behavioural control with regard to attending an appointment for mammography. A tertile split was performed to divide the sample into those who reported a higher level of perceived control over the target behaviour (range $=40-42$ ), and those who reported lower perceived behavioural control (range $=14-33$ ). Participants who scored in the second tertile (scores of 34-39) were excluded from this analysis. The mean perceived behavioural control scores were significantly different between the two remaining groups, $F(1,78)=333.04, p<0.01$ (Table 4).

Based on a Chi Squared analysis, $56 \%$ of participants with higher perceived behavioural control initiated upward family communication about mammography,

Table 4. Descriptive statistics of baseline perceived behavioural control scores and outcomes by condition and $\mathrm{PBC}$ group.

\begin{tabular}{lcc}
\hline & \multicolumn{2}{c}{ Condition } \\
\cline { 2 - 3 } PBC group & Experimental & Control \\
\hline Higher PBC & 22 & \\
$N$ & 41.41 & 19 \\
$M$ & 0.80 & 41.00 \\
SD & $73 \%$ & 0.88 \\
Proportion of participants who initiated conversation & & $37 \%$ \\
Lower PBC & 19 & 20 \\
$N$ & 27.42 & 26.95 \\
$M$ & 5.11 & 4.71 \\
SD & $26 \%$ & $20 \%$ \\
Proportion of participants who initiated conversation & & \\
\hline
\end{tabular}


compared to just $23 \%$ of participants with lower perceived behavioural control, $\chi^{2}(1)=9.08, p<0.01$. Separate Chi Squared analyses were also performed on each of the two perceived behavioural control groups, with conversation and condition as the categorical variables. Within the lower perceived behavioural control group, participants in the experimental condition were no more likely to have initiated upward family communication about mammography than control participants $[20 \%$ of control participants versus $26 \%$ of experimental participants, $\chi^{2}(1)=0.22$, $p>0.05$ ], a result that is inconsistent with Rutter et al.'s (2007) findings. However, within the higher perceived behavioural group, experimental participants were more likely to have initiated the desired conversation, with $73 \%$ of experimental participants having successfully performed the behaviour as compared to $37 \%$ of control participants, $\chi^{2}(1)=5.33, p<0.05$. Thus, the II intervention was most successful for participants who reported a higher level of perceived behavioural control at Stage One.

\section{Discussion}

The results of the current study add to an already substantial body of research that supports the TPB (Armitage \& Conner, 2000, 2001; Conner \& Sparks, 1996; Godin \& Kok, 1996). With the exception of subjective norm, the relationships between variables were consistent with those posited by the TPB model. Only attitude and perceived behavioural control were significant independent predictors of intention scores. These results are consistent with findings from a meta-analytic review of 185 TPB studies, which found that subjective norm is often a weaker predictor of intention, and therefore behaviour (Armitage \& Conner, 2001). It is possible that in the current study, the behaviour targeted was so novel that participants had not given the issue of upward family communication much consideration prior to participation in the study, and thus found it difficult to conceptualise how significant others would evaluate the behaviour. More groundwork may be necessary with younger women to increase their level of engagement with the issue prior to being prompted to initiate upward family communication about mammography. It is also possible that this result was an artefact of measurement, given that subjective norm was measured using only one item.

Further, the findings of the current study add to the existing evidence that the TPB has utility in predicting health-related and communication behaviour (e.g. Barsevick et al., 2008; Hyde \& White, 2009), and provide new evidence that the TPB is useful for predicting upward family communication about mammography. Participants who reported a higher level of perceived control over the desired behaviour were more likely to initiate upward family communication about mammography than those who reported lower perceived behavioural control, however no difference was evident between high and low intenders. Ajzen (1991) posits that in situations where actual volitional control over the behaviour is reduced, perceived behavioural control is likely to emerge as a stronger predictor relative to intention, a prediction that is supported by the results of the current study. Volitional control may be reduced when successful performance of the behaviour is not wholly dependent on the actor, and relies on other external variables. Indeed, the successful performance of the target behaviour in the current study was not reliant on the participant alone, but also on factors such as spending time with an older female relative within the present study's timeframe, and the relative's openness to 
participating in a conversation about mammography. Therefore, even young women with the best of intentions to initiate upward family communication about mammography may be prevented from doing so by external factors.

Previously, IIs have been used to facilitate performance of behaviours that are wholly or predominantly reliant upon one's own decision-making, such as studying (Sheeran, Webb, \& Gollwitzer, 2005), eating fruit and vegetables (Armitage, 2006), quitting smoking (Armitage, 2007), and having a mammogram (Rutter et al., 2007). These behaviours do not fundamentally require the participation or cooperation of another person in the way that everyday health communication does. It is therefore possible that the effectiveness of IIs is reduced when intention is not the primary predictor of behaviour, and when other factors (or other people) hinder one's ability to implement an action plan.

It was hypothesised that those who formed IIs would be more likely to enact the desired behaviour. Experimental condition was retained as a predictor in the final logistic model, and the independent contribution made to behavioural prediction was marginally significant. This result indicates a trend for those who formed IIs to be more likely to initiate a conversation about mammography with an older female family member, which is preliminary evidence for the success of using IIs to increase performance of this behaviour. These results both provide the foundation for future II intervention research in the context of upward family communication about mammography, and also highlight a potentially useful mammography promotion strategy for practitioners working with families in the context of breast cancer, or maybe even other screening behaviours.

Gollwitzer (1993) specified that IIs operate volitionally. This mechanism presupposes the presence of intention, and explains that IIs work by converting intention into behaviour. However, participants in our study who reported baseline levels of intention in the lowest tertile (low intenders) were more likely to be susceptible to the effect of IIs than those with an intention score in the highest tertile (high intenders). In fact, within the current study, the II intervention did not work for high intenders. Within this group, those who formed IIs were no more likely to initiate the desired behaviour than controls, though there was a trend in the anticipated direction. In contrast, low intenders who formed IIs were more likely to have initiated a conversation about mammography than low intender controls, indicating that the intervention was more successful for those who reported lower levels of intention to perform the behaviour at baseline. While this pattern of results is inconsistent with much previous work which has demonstrated that IIs have most utility for those with high intention at baseline (e.g. Armitage, 2006, 2007; Sheeran et al., 2005), at least one previous study also found that an II intervention was most effective for low intenders (Rutter, Steadman, \& Field, 2002). One possible explanation for this unexpected result is that in the current study, IIs operated motivationally (by raising levels of intention amongst low intenders) and not volitionally (by converting intention into behaviour). This is unlikely however, because while overall intention scores rose between Stages One and Two, this effect did not differ between experimental groups. Previous published work has likewise established that IIs do not increase one's motivation to perform the behaviour (e.g. Orbell et al., 1997; Sheeran et al., 2005; Steadman \& Quine, 2004).

Another potential explanation for the result is that it is a reflection of ceiling effects in the intender group, however the modest figures displayed in Table 3 suggest this is also unlikely. Thus, neither motivational nor ceiling effects can account for the 
unusual pattern of experimental effects observed in this study. It may be that the nature of the target behaviour, being somewhat altruistic, influenced the pattern of results so that they were not wholly consistent with the findings of past research. It may be that with altruistic behaviours, as with behaviours that are not wholly under volitional control, research attention should extend beyond the intention-behaviour relationship and more comprehensively explore the relationship between other social cognitive variables (such as perceived behavioural control and norms) with behaviour.

A novel finding of the present study was that the II intervention was more effective for those who reported higher perceived behavioural control at baseline. Rutter et al.'s (2007) II study that aimed to increase mammography screening also found that the effects of the II intervention varied with perceived behavioural control scores. However, in contrast to the results of the current study, Rutter et al.'s results indicated that the II intervention worked best for women with low perceived behavioural control pre-intervention. This variation in patterns of results may be attributable to the nature of the target behaviour, in that upward family communication is not wholly under volitional control, as explained above. When considering having a mammogram, low perceived behavioural control is likely to reflect perceived lack of control rather than an actual lack of control over the behaviour (e.g. being too busy, not knowing how to arrange an appointment). Forming IIs may have facilitated mammography screening behaviour by assisting women to identify, and plan strategies to overcome, perceived barriers. As outlined above, it is probable that some of the barriers to engaging in upward family communication are external and out of the young woman's control, and therefore less likely to be influenced by the formation of an II.

In light of these findings, an interesting avenue for future work would be to include pre- and post-test measures of perceived behavioural control in II intervention studies, a method that has been adopted by other II researchers (e.g. Rutter et al., 2006, 2007). Further, the content or context of IIs could be manipulated by guiding participants to form more complex IIs in two steps: (1) identification of prominent barriers or interferences (e.g. nervousness), and (2) forming the II within the context of the specific barrier or interference. Comparing the effectiveness of IIs that address potential barriers or interferences (e.g. 'When I get nervous about raising the topic of mammography with my mum after we eat dinner, I will remind myself that mammography is a normal part of a woman's life') with IIs that do not (e.g. 'I will raise the topic of mammography with my mother when we talk after dinner') would be an valuable next step in the design and evaluation of II interventions. While the relationship between intention and IIs should not be neglected, future work should certainly include the examination of the relationship between perceived behavioural control and IIs, especially with regard to complex behaviours that are not wholly under volitional control.

Future work may also benefit from giving consideration to the nature of the cues identified in the action plan. Recent evidence suggests that a standard II that identifies situational cues to behaviour is not substantially more effective at bridging the intention-behaviour gap than a global commitment to engaging in the target behaviour (Ajzen, Czasch, \& Flood, 2009; Chapman, Armitage, \& Norman, 2009). These findings suggest that, contrary to initial belief, the identification of specific external cues is not necessary for IIs to be effective in converting intention to behaviour (see also Papies, Aarts, \& de Vries, 2009). 
Also in line with these findings is the work of Adriaanse et al. (2009), who found that IIs that identified motivational cues for snacking ('why', e.g. feeling bored or wanting to be social) were more successful in facilitating healthier snacking habits than IIs that identified traditional situational cues ('when' and 'where', e.g. at home, when alone). They posit that motivational cues for implementing complex behaviour change may be more important than situational cues. Such work represents the synergy of motivational and volitional attempts at facilitating behaviour change. Subsequent II research may benefit from the inclusion of motivational cues as part of the II formulation. This may be particularly relevant for interventions that aim to facilitate the complex behaviour of upward family communication about mammography, as a discussion of this nature is likely to be emotive, and therefore guiding young women to form IIs that identify internal, motivational cues (e.g. 'I will initiate a conversation about mammography with my mother because I'm fearful of losing her to breast cancer at a young age' or 'I will talk to my mother about mammography as I want to build a close relationship with her and show her I care') may be particularly effective at translating intention into behaviour.

\section{Limitations and future directions}

Being limited in access to the younger women (participants) only, it was not possible to conduct follow-up with their conversation partners (mostly their mothers). The primary motivation for trialling an upward family communication intervention was to influence more target women to have mammograms. Therefore it would have been interesting to have baseline data from the older female family members that measured their mammography awareness, previous screening behaviour, attitudes and beliefs towards the behaviour, and also to conduct a follow-up (e.g. at three months post-conversation) to obtain self-report data about any changes in these variables, or indeed changes in screening behaviour. Inclusion of the conversation partner in the study should be a vital part of more comprehensive research in the future. Another advantage of including the older female family members as participants in future similar studies is that it would permit validation of the daughters' self-reports of whether or not they did initiate a conversation about mammography. The reliance on daughters' self-report in the current study is a limitation.

Additionally, this study did not measure participants' behaviour in light of the individual IIs they formed. Participants were not specifically asked to report on the circumstances surrounding the conversation they initiated with an older female family member at Stage Two. This eliminated the possibility of systematically testing the notion that the cues specified in the II triggered or elicited the desired behaviour once encountered. A small number of participants supplied this information spontaneously, but the sample was too small to readily enable any systematic analyses to be conducted.

The generalisability of our results may be impacted by the university student sample, however this population would be an ideal target group for such an intervention. The results of the current study demonstrate that an upward family communication approach to promoting mammography is viable. Targeting university students, particularly those who are the first woman in their family to be tertiary educated, may be an especially powerful approach as mothers report having respect 
for their daughters' higher education and looking to them for health-related advice (Browne \& Chan, 2011; Mosavel, 2009; Washington et al., 2009)

Finally, the experimenter was not blind to condition. However, efforts were made to minimise the likelihood of experimenter demand effects by presenting the condition-specific instructions and tasks via the questionnaire booklets.

\section{Conclusions}

The current study provides new, though preliminary, evidence that the TPB has good utility for predicting upward family communication about mammography. This study also provides the first evidence that IIs may be able to facilitate upward family communication about mammography, which has the potential to be an effective mammography promotion strategy. Perceived behavioural control emerged as the most important variable in predicting this target communication behaviour. The altruistic nature of this behaviour, and the fact that it is not wholly under volitional control, may have contributed to this finding. Future studies that systematically explore the relative roles of intention and perceived behavioural control in behaviours of this nature are warranted.

\section{Acknowledgements}

The authors acknowledge the contribution of Prof Sandra Jones to the supervision of the PhD research project of which the study reported in this article was a part.

\section{References}

Adriaanse, M.A., de Ridder, T.D., \& de Wit, J.B.F. (2009). Finding the critical cue: Implementation intentions to change one's diet work best when tailored to personally relevant reasons for unhealthy eating. Personality and Social Psychology Bulletin, 35, $60-71$.

Ajzen, I. (1991). The theory of planned behavior. Organizational Behavior and Human Decision Processes, 50, 119-211.

Ajzen, I., Czasch, C., \& Flood, M.G. (2009). From intentions to behavior: Implementation intention, commitment, and conscientiousness. Journal of Applied Social Psychology, 39, 1356-1372.

Ajzen, I., \& Fishbein, M. (1980). Understanding attitudes and predicting social behavior. Englewood Cliffs, NJ: Prentice-Hall.

Ajzen, I., \& Madden, T.J. (1986). Prediction of goal-directed behavior: Attitudes, intentions, and perceived behavioral control. Journal of Experimental Social Psychology, 22, 453-474.

Arbour, K.P., \& Ginis, K.A.M. (2009). A randomised controlled trial of the effects of implementation intentions on women's walking behaviour. Psychology and Health, 24, 49-65.

Armitage, C.J. (2006). Evidence that implementation intentions promote transitions through the stages of change. Journal of Consulting and Clinical Psychology, 74, 141-151.

Armitage, C.J. (2007). Effects of an implementation intention-based intervention on fruit consumption. Psychology and Health, 22, 917-928.

Armitage, C.J., \& Conner, M. (2000). Social cognition models and health behaviour: A structured review. Psychology and Health, 15, 173-189. 
Armitage, C.J., \& Conner, M. (2001). Efficacy of the theory of planned behaviour: A metaanalytic review. British Journal of Social Psychology, 40, 471-499.

Australian Institute of Health and Welfare \& National Breast and Ovarian Cancer Centre (2009). Breast cancer in Australia: an overview, 2009. Canberra: Australian Institute of Health and Welfare.

Barsevick, A.M., Montgomery, S.V., Ruth, K., Ross, E.A., Egleson, B.L., Bingler, R.,..., Daly, M.B. (2008). Intention to communicate BRCA1/BRCA2 genetic test results to the family. Journal of Family Psychology, 22, 303-312.

Brandstatter, V., Lengfelder, A., \& Gollwitzer, P.M. (2001). Implementation intentions and efficient action initiation. Journal of Personality and Social Psychology, 81, 946-960.

Brickell, T.A., Chatzisarantis, N.L.D., \& Pretty, G.M. (2006). Using past behaviour and spontaneous implementation intentions to enhance the utility of the theory of planned behaviour in predicting exercise. British Journal of Health Psychology, 11, 249-262.

Browne, J.L., \& Chan, A.Y.C. (2011). Mother-daughter communication about mammography in an Australian sample. Journal of Family Communication, in press.

Cancer Research UK (2007). CancerStats - Mortality. London: Cancer Research UK.

Chapman, J., Armitage, C.J., \& Norman, P. (2009). Comparing implementation intention interventions in relation to young adults' intake of fruit and vegetables. Psychology and Health, 24, 317-332.

Conner, M., \& Armitage, C.J. (1998). Extending the Theory of Planned Behavior: A review and avenues for further research. Journal of Applied Social Psychology, 28, $1429-1464$.

Conner, M., \& Norman, P. (2005). Predicting health behaviour: A social cognition approach. In M. Conner \& P. Norman (Eds.), Predicting health behaviour: Research and practice with social cognition models (2nd ed., pp. 1-27). Buckingham: Open University Press.

Conner, M., \& Sparks, P. (1996). The theory of planned behaviour and health behaviours. In M. Conner \& P. Norman (Eds.), Predicting health behaviour: Research and practice with social cognition models (2nd ed., pp. 121-162). Buckingham, UK: Open University Press.

Cooke, R., \& French, D.P. (2008). How well do the theory of reasoned action and theory of planned behaviour predict intentions and attendance at screening programmes? A metaanalysis. Psychology and Health, 23, 745-765.

de Nooijer, J., de Vet, E., Brug, J., \& de Vries, N.K. (2006). Do implementation intentions help to turn good intentions into high fruit intakes? Journal of Nutrition Education and Behavior, 38, 25-29.

Epstude, K., \& Roese, N.J. (2008). The functional theory of counterfactual thinking. Personality and Social Psychology Review, 12, 168-192.

Fingerman, K.L. (1997). Being more than a daughter: Middle-aged women's conceptions of their mothers. Journal of Women and Aging, 9, 55-72.

Fingerman, K.L. (2001). Aging mothers and their adult daughters: A study in mixed emotions. New York: Springer.

Godin, G., \& Kok, G. (1996). The theory of planned behavior: A review of its applications to health-related behaviors. American Journal of Health Promotion, 11, 87-98.

Gollwitzer, P.M. (1993). Goal achievement: The role of intentions. In W. Stroebe \& M. Hewstone (Eds.), European review of social psychology (Vol. 4, pp. 141-185). London: Wiley.

Gollwitzer, P.M. (1999). Implementation intentions. Strong effects of simple plans. American Psychologist, 54, 493-503.

Hardeman, W., Johnston, M., Johnston, D., Bonetti, D., Wareham, N., \& Kinmonth, A.L. (2002). Application of the Theory of Planned Behaviour in behaviour change interventions: A systematic review. Psychology and Health, 17, 123-158.

Horner, M.J., Ries, L.A.G., Krapcho, M., Neyman, N., Aminou, R., Howlader, N.,..., Edwards, B.K. (2009). SEER cancer statistics review, 1975-2006. Bethesda, MD: National Cancer Institute. 
Hosmer, D.W., \& Lemeshow, S. (1989). Applied logistic regression. Canada: Wiley and Sons.

Humphrey, L.L., Helfand, M., Chan, B.K., \& Woolf, S.H. (2002). Breast cancer screening: A summary of the evidence for the US Preventive Services Task Force. Annals of Internal Medicine, 137, 347-360.

Hyde, M.K., \& White, K.M. (2009). To be a donor or not to be? Applying an extended Theory of Planned Behavior to predict posthumous organ donation intentions. Journal of Applied Social Psychology, 39, 880-900.

Kerlikowske, K., Grady, D., Rubin, S.M., Sandrock, C., \& Ernster, V. (1995). Efficacy of screening mammography: A meta-analysis. Journal of the American Medical Association, $273,149-154$.

McGraw, L.A., \& Walker, A.J. (2004). Negotiating care: Ties between white aging mothers and their caregiving daughters. The Journals of Gerontology Series B: Psychological Sciences and Social Sciences, 59, S324-S332.

McPherson, K., Steel, C.M., \& Dixon, J.M. (2000). Breast cancer - epidemiology, risk factors, and genetics. British Medical Journal, 321, 624-628.

Milne, S., Orbell, S., \& Sheeran, P. (2002). Combining motivational and volitional interventions to promote exercise participation: Protection motivation theory and implementation intentions. British Journal of Health Psychology, 7, 163-184.

Mosavel, M. (2009). The feasibility of mothers accepting health advice from their adolescent daughters. Journal of Health Care for the Poor and Underserved, 20, 42-49.

Mosavel, M., Simon, C., \& Van Stade, D. (2006). The mother-daughter relationship: What is its potential as a locus for health promotion? Health Care for Women International, 27, 646-664.

Mosavel, M., \& Thomas, T. (2009). Daughter-initiated health advice to mothers: Perceptions of African-American and Latina daughters. Health Education Research, 24, 799-810.

National Cancer Institute (2004). Breast cancer progress report. Washington, DC: US Department of Health and Human Services.

National Health Service (2009). Expanding our reach: NHS Breast Screening Programme annual review 2009. NHS.

Orbell, S., Hodgkins, S., \& Sheeran, P. (1997). Implementation intentions and the Theory of Planned Behavior. Personality and Social Psychology Bulletin, 23, 945-954.

Page, C.M., \& Colby, P.M. (2003). If only I hadn't smoked: The impact of counterfactual thinking on a smoking-related behavior. Psychology and Marketing, 20, 955-976.

Papies, E.K., Aarts, H., \& de Vries, N.K. (2009). Planning is for doing: Implementation intentions go beyond the mere creation of goal-directed associations. Journal of Experimental Social Psychology, 45, 1148-1151.

Parker, D., Stradling, S.G., \& Manstead, A.S.R. (1996). Modifying beliefs and attitudes to exceeding the speed limit: An intervention study based on the Theory of Planned Behavior. Journal of Applied Social Psychology, 26(1), 1-19.

Prestwich, A., Conner, M., Lawton, R., Bailey, W., Litman, J., \& Molyneaux, V. (2005). Individual and collaborative implementation intentions and the promotion of breast selfexamination. Psychology and Health, 20, 743-760.

Renner, B., \& Schwarzer, R. (2003). Social cognitive factors in health behavior change. In J. Suls \& K. Wallston (Eds.), Social psychological foundations of health and illness (pp. 169-196). Oxford: Blackwell.

Rimer, B.K. (1998). Interventions to enhance cancer screening: A brief a review of what works and what is on the horizon. Cancer, 83, 1770-1774.

Rise, J., Thompson, M., \& Verplanken, B. (2003). Measuring implementation intentions in the context of the theory of planned behavior. Scandinavian Journal of Psychology, 44, 87-95.

Rutter, D., Quine, L., Steadman, L., \& Thompson, S. (2007). Increasing attendance at breast cancer screening: Field trial. Canterbury: University of Kent.

Rutter, D., Steadman, L., \& Field, S. (2002). An intervention to increase breast screening uptake. Canterbury: University of Kent. 
Rutter, D.R., Steadman, L., \& Quine, L. (2006). An implementation intentions intervention to increase uptake of mammography. Annals of Behavioral Medicine, 32, 127-134.

Sheeran, P., \& Orbell, S. (1998). Do intentions predict condom use? Meta-analysis and examination of six moderator variables. British Journal of Social Psychology, 37, 231-250.

Sheeran, P., \& Orbell, S. (2000). Using implementation intentions to increase attendance for cervical cancer screening. Health Psychology, 19, 283-289.

Sheeran, P., \& Silverman, M. (2003). Evaluation of three interventions to promote workplace health and safety: Evidence for the utility of implementation intentions. Social Science \& Medicine, 56, 2153-2163.

Sheeran, P., Webb, T.L., \& Gollwitzer, P.M. (2005). The interplay between goal intentions and implementation intentions. Personality and Social Psychology Bulletin, 31, 87-98.

Simmons, S., \& Robson, B. (2008). Independent Maori monitoring report 1: BreastScreen Aotearoa July 2004 to June 2006 50-64 years. Wellington: Te Ropu Rangahau Hauora a Eru Pomare.

Steadman, L., \& Quine, L. (2004). Encouraging young males to perform testicular selfexamination: A simple, but effective, implementation intentions intervention. British Journal of Health Psychology, 9, 479-487.

Van Osch, L., Reubsaet, A., Lechner, L., Candel, M., Mercken, L., \& De Vries, H. (2008). Predicting parental sunscreen use: Disentangling the role of action planning in the intention-behavior relationship. Psychology and Health, 23, 829-847.

Washington, P.K., Burke, N.J., Joseph, G., Guerra, C., \& Pasick, R.J. (2009). Adult daughters' influence on mothers' health-related decision making: An expansion of the subjective norms construct. Health Education and Behavior, 36, 129S-144S.

Webb, T.L., \& Sheeran, P. (2006). Does changing behavioral intentions engender behavior change? A meta-analysis of the experimental evidence. Psychological Bulletin, 132, 249-268.

Wiedemann, A.U., Schüz, B., Sniehotta, F., Scholz, U., \& Schwarzer, R. (2009). Disentangling the relation between intentions, planning, and behaviour: A moderated mediation analysis. Psychology and Health, 24, 67-79. 